\title{
JP2SD
}

\section{JURNAL PEMIKIRAN dan PENGEMBANGAN SEKOLAH DASAR \\ ISSN 2338-1140 \\ Jilid 1, Nomor 1, April 2013, hlm. 1-75}

\section{DAFTAR ISI}

Pengembangan Gerak Dasar Renang untuk Anak Sekolah Dasar

Bustanol Arifin

Pembelajaran Keliling Bangun Datar Menurut Standar

$9-14$

National Council of Teachers of Mathematics (NCTM) dengan Setting Kooperatif

pada Siswa Kelas 3 SD Muhammadiyah 9 Malang

Dyah Worowirastri Ekowati

Peningkatan Kemampuan Guru Sekolah Dasar Muhammadiyah dalam Pengembangan

Kurikulum Muatan Lokal

Elly Purwanti

Pengembangan Model Pembinaan SD Muhammadiyah di Malang Raya

Untuk Menjadi Sekolah PPL Bagi Mahasiswa PGSD-UMM

Endang Poerwanti

Pembelajaran Kooperatif Model STAD-Problem Solving untuk Meningkatkan

Motivasi dan Hasil Belajar Matematika pada Siswa Kelas IV

SD Muhammadiyah 8 DAU Malang

Erna Yayuk

Integrasi Pendidikan Karakter ke dalam Pembelajaran Kewarganegaraan di Sekolah Dasar

Machful Indra Kurniawan

Model Pembelajaran Pendidikan Karakter pada Pembelajaran Tematik di

SD Muhammadiyah 9 kota Malang

Rina Wahyu Setyaningrum \& Husamah

Penerapan Strategi Multiple Games untuk Meningkatkan Kemampuan Membaca Permulaan

Siswa Kelas I SD Negeri Penanggungan Malang

Sri Agustin Mulyani

Program Bimbingan dan Konseling di Sekolah Dasar

Widada 


\section{Petunjuk bagi (Calon) Penulis JURNAL PEMIKIRAN DAN PENGEMBANGAN SEKOLAH DASAR (JP2SD)}

1. Artikel yang ditulis untuk JP2SD meliputi hasil telah (hanya atas undangan) dan hasil penelitian di bidang kependidikan Naskah diketik dengan program Microsoft Word, huruf Times New Roman, ukuran 12 pts, dengan spasi ganda, dicetak pada kertas A4 dengan panjang maksimum 38 halaman, dan diserahkan dalam bentuk Print-out sebanyak 3 eksemplar beserta Soft-copy-nya. Pengirim naskah juga dapat dilakukan sebagai attachment e-mail ke alamat: pgsd@umm.ac.id

2. Artikel ditulis dalam bahasa indonesia atau inggris. Sistematika artikel hasil penelitian adalah judul, nama penulis, abstrak disertai kata kunci, pendahuluan, metode, hasil dan pembahasan, simpulan, serta daftar rujukan.

3. Judul artikel dalam bahasa indonesia tidak boleh lebih dari 14 kata, sedangkan judul dalam bahasa inggris tidak boleh lebih dari 12 kata. Judul dicetak dengan huruf kapital di tengah-tengah, dengan jukuran huruf 14 poin.

4. Nama penulis dicantumkan tanpa gelar akademik, disertai lembaga asal, dan ditempatkan dibawah judul artikel. Dalam hal naskah ditulis oleh tim, penyunting hanya berhubungan dengan penulis utama atau penulis yang namanya tercantum pada urutan pertama. Penulis pertama harus mencantumkan alamat korespondensi atau e-mail.

5. Abstrak dan kata kunci ditulis dalam dua bahasa (Indonesia dan Inggris). Panjang masing-masing abstrak 75-100 kata, sedangkan jumlah kata kunci 3-5 kata. Abstrak minimal berisi judul, tujuan, metode, dan hasil penelitian.

6. Bagian pendahuluan berisi latar belakang, konteks penelitian, hasil kajian pustaka, dan tujuan penelitian. Seluruh bagian pendahuluan dipaparkan secara terintegrasi dalam bentuk paragraf-paragraf, dengan panjang $15-20 \%$ dari total panjang artikel.

7. Bagian metode berisi paparan dalam bentuk paragraf tentang rancangan penelitian, sumber data, teknik pengumpulan data, dan analisis data yang secara nyata dilakukan peneliti, dengan panjang 10-15\% dari total panjang artikel.

8. Bagian hasil penelitian berisi paparan hasil analisis yang berkaitan dengan pertanyaan penelitian. Setiap hasil penelitian harus dibahas. Pembahasan berisi pemaknaan hasil dan perbandingan dengan teori dan/atau hasil penelitian sejenis. Panjang paparan berhasil dan pembahasan $40-60 \%$ dari panjang artikel.

9. Bagian simpulan berisi temuan penelitian yang berupa jawaban atas pertanyaan penelitian atau berupa intisari hasil pembahasan. Simpulan disajikan dalam bentuk paragraf.

10. Daftar rujukan hanya memuat sumber-sumber yang dirujuk, dan semua sumber yang dirujuk harus tercantum dalam daftar rujukan. Sumber rujukan minimal $80 \%$ berupa pustaka terbitan 10 tahun terakhir. Rujukan yang digunakan adalah sumber-sumber primer berupa artikel-artikel penelitian dalam jurnal atau laporan penelitian(termasuk skripsi, tesis, disertasi). Artikel yang dimuat di Jurnal Pemikiran dan Pengembangan Sekolah Dasra disarankan untuk digunakan sebagai rujukan.

11. Perujukan dan pengutipan menggunakan teknik rujukan berkurung (nama akhir, tahun). Pencantuman sumber pada kutipan langsung hendaknya disertai keterangan tentang nomor halaman tempat asal kutipan. Contoh: (Davis, 2003: 47).

12. Daftar rujukan disusun dengan tata cara seperti contoh berikut ini diurutkan secara alfabetis dan kronologis.

Buku:

Anderson, D.W.; Vault V.D.; \& Dickson, C.E. 1999. Problems and Prospects for the Decades Ahead: Competency Based Teacher Education. Berkeley: McCuthan Publishing Co.

Buku kumpulan artikel:

Saukah, A. \& Waseso, M.G. (Eds.). 2002. Menulis Artikel untuk Jurnal Ilmiah (Edisi ke-4, cetakan ke1). Malang: UM Press.

Artikel dalam jurnal atau majalah: 
Kansil, C.L. 2002. Orientasi Baru Penyelenggaran Pendidikan Program Profesional dalam Memenuhi Kebutuhan Dunia Industri. Transpor, XX (4): 57-61

Artikel dalam koran:

Pitunov, B. 13 Desember, 2002. Sekolah Unggulan ataukah sekolah Pengunggulan? Majapahit Pos, hlm.4 \& 11.

Tulisan/berita dalam koran (tanpa nama pengarang):

Jawa Pos. 22 April, 1995. Wanita Kelas Bawah Lebih Mandiri, hlm.3

Dokumen resmi:

Pusat Pembinaan dan Pengembangan Bahasa. 1978. Pedoman Penulisan Laporan Penelitian. Jakarta: Depdikbud. Undang-undang Republik Indonesi Nomer 2 Tentang Sistem Pendidikan Nasional. 1990. Jakarta: PT Amas Duta Jaya.

Buku terjemahan:

Ary,D.; Jacobs'l.C.; \& Razaveih, A. 1976. Pengantar Penelitian Pendidikan. Terjemahan oleh Arief Furochan. 1982. Surabaya: Usaha Nasional.

Skripsi, Tesis, Desertasi, Laporan Penelitian:

Kuncoro, T. 1996. Pengembangan Kurikulum Penelitian Magang di STM Masional Malang Jurusan Bangunan,Program Studi Bangunan Gedung: Suatu Studi Berdasarkan Kebutuhan Dunia Usaha Jasa Konstruksi. Tesis tidak diterbitkan. Malang: PPS IKIP MALANG.

Makalah Seminar, lokakarya, penatara:

Waseso, M. G. 2001. Isi dan Format Jurnal Ilmiah, makalah disajikan dalam Seminar Lokakarya Penulisan Artikel dan Pengelolaan Jurnal Ilmiah, Universitas Lambungmangkurat, Banjarmasin, 9-11 Agustus.

Internet(Karya individual):

Hichock, S.; Carr, L.; \& hall, W . 1996. A Survey of STM Online Jurnals, 1990-1995:The Calm before the strorm, (Online), (http://journal.ecs.soton.ac.uk/survey/survey.html, diaskes 12 juni 1996).

Internet (artikel dalam jurnal online):

Kumaidi. 1998. Pengukuran Bekal Awal Belajar dan Pengembangan Tesnya. Jurnal Ilmu Pendidikan. (Online), Jilid 5, No.4 (http://www.malang.ac.id, dikses 20 januari 2000).

Internet (bahan diskusi):

Wilson, D. 20 Noveber 1995 . Summary of Citing Internet Sites. NETTRAIN Discusion List, (Online), (NETTRIAIN@ubvm.cc.buffalo.edu diaskes 22 November 1995).

Internet (e-mail pribadi):

Naga, D.S. (kip-jkt@indo.net.id). 1 Oktober 1997. Artikel untuk JP2SD. E-mail kepada Ali Saukah (jippsi@mlg.ywcn.or.id).

13. Tata cara penyajian kutipan, rujukan,tabel dan gambar mengikuti ketentuan dalam Pedoman penulisan Karya Ilmiah dimuat. Artikel berbahasa Indonesia mengunakan Pedoman Umum Ejaan Bahasa Indonesia yang disempurnakan dan istilah-istilah yang dibakukan oleh Pusat bahasa.

14. Semua naskah ditelaah secara anonim oleh mitra oleh mitra bebestari (reviewers) yang ditunjuk oleh penyuting bidang kepakarannya. Penulis artikel diberi kesempatan untuk melakukan perbaikan (revisi ) naskah atas dasar rekomendasi/saran dari mitra bebestari atau penyunting.Kepastian pemuatan atau penolakan naskah akan diberitahukan secera tertulis.

15. Segala sesuatu yang menyangkut perizinan pengutipan atau penggunaan Software komputer untuk pembuatan naskah atau ihwal lain yang terkait dengan HaKI yang dilakukan oleh penulis artikel, berikut konsekuensi hukum yang mungkin timbul karenanya, menjadi tanggung jawab penuh penulis artikel. 